\title{
Role of Neostigmine in Neurotoxic Snake Bite
}

\author{
Irshad V.S. ${ }^{1}$, Parth Godhiwala ${ }^{2}$, Sunil Kumar ${ }^{3}$, Charan Singh Bagga ${ }^{4}$, Anusha Gupta ${ }^{5}$ \\ 1,2,3,4,5 Department of Medicine, Jawaharlal Nehru Medical College, Datta Meghe Institute of Medical Sciences \\ (Deemed to Be University), Wardha, Maharashtra, India.
}

\section{INTRODUCTION}

Snake bite is a major health concern in India. Common krait is one of the most dangerous and poisonous neurotoxic snakes. Snake bite is a medical emergency. India has the highest snake bite death rate in the world..$^{1}$ Elapidae, viperidae, pit viper and hydrophiidae are the main poisonous snake families in India.

Elapidae family includes common cobra, king cobra and common krait. ${ }^{2}$ Common Indian krait is about 10 times more poisonous than cobra. Snake toxins are neurotoxic or haematotoxic. Krait is neurotoxic, which interrupts neuromuscular transmission of impulse and causes paralysis of muscles. Neostigmine which is an anticholinesterase can reverse the neurological manifestations of the venom. ${ }^{3}$ Treatment of neurotoxic snake bite includes administration of anti-snake venom, neostigmine with atropine and invasive ventilation if there is respiratory muscle weakness or paralysis. Maximum dose of neostigmine to reverse neuromuscular blockade is $10 \mathrm{mg}$ over 24 hours. ${ }^{4}$ Here we report a case of a 60 -years-old male who presented with a snake bite followed by respiratory distress and bilateral ptosis. The patient was treated as per standard protocol. However, his ptosis did not improve as per expectations. Hence, neostigmine was given for prolonged period to revert ptosis in neurotoxic snake bite. In this case study we are discussing about maximum dose of neostigmine given to revert ptosis in a neurotoxic snake bite, as their no case report regarding it.

\section{PRESENTATION OF CASE}

A sixty-year-old male, came to casualty of AVBRH hospital Sawangi, in the morning at 7 am with c / o difficulty in breathing, swallowing and drooping of eyelids. Patient had alleged history of snake bite on the anterior aspect on the left shoulder, at his home in the early morning at about $1 \mathrm{am}$ while he was sleeping. Patient was taken to a local hospital and first aid was given after which the patient was referred to our hospital for further management. He recalled the snake as a common krait. There was no history of pain, redness, sweating, necrosis, paraesthesia, giddiness or syncope, nausea, vomiting, abdominal colic, bleeding from any orifice, or swelling. There was no history of hypertension, diabetes mellitus, tuberculosis, asthma and any cerebrovascular episodes that could have caused neurological deficit.

On examination, Pulse - 80 / min, regular, normal volume, BP - 120 / 80 mm Hg, no pallor, icterus, cyanosis, clubbing and lymphadenopathy. There was no sign of inflammation and paraesthesia around the bite mark. On systemic examination, his cardiovascular system, respiratory system and abdominal system were normal. He was conscious, oriented, having 5 / 5 power in all group of muscles and bilateral plantar were flexors. All routine investigation was within normal limits. Whole blood clotting time was done 6 hourly and was less than 6 minutes.
Corresponding Author:

Parth Godhiwala,

Post Graduate Resident,

Department of Medicine,

Jawaharlal Nehru Medical College,

Datta Meghe Institute of Medical

Sciences (Deemed to Be University),

Wardha, Maharashtra, India.

E-mail: persie_parth@yahoo.in

DOI: $10.14260 / j e m d s / 2021 / 234$

How to Cite This Article:

Irshad VS, Godhiwala P, Kumar S, et al. Role of neostigmine in neurotoxic snake bite. J Evolution Med Dent Sci 2021;10(15):10951097, DOI: 10.14260/jemds/2021/234

Submission 28-10-2020,

Peer Review 16-02-2021,

Acceptance 23-02-2021,

Published 12-04-2021.

Copyright (c) 2021 Irshad V.S. et al. This is an open access article distributed under Creative Commons Attribution License [Attribution 4.0 International (CC BY 4.0)] 


\section{DISCUSSION OF MANAGEMENT}

After few minutes of hospital admission, the patient had tachypnoea, tachycardia, bilateral ptosis and became unconscious. So, the patient was intubated and put on mechanical ventilator. We administered 10 vials of anti-snake venom (ASV) diluted in $250 \mathrm{ml}$ of normal saline after sensitivity testing, along with inj. atropine, inj. neostigmine, iv antibiotics and iv fluids. Another dose of anti-snake venom was administered, in the form of 10 vials, after 6 hours, followed by 10 more vials after 12 hours. For ptosis, cycles of inj neostigmine were started, each cycle constituted of inj neostigmine $0.5 \mathrm{mg}$ every half hourly, total of 5 doses and each cycle was repeated after 4 hours. After 48 hours of hospital stay patient started showing improvement. Patient became conscious, obeyed commands, moved all limbs. Ptosis remained persistent and didn't show any improvement even after 48 hours of neostigmine therapy, dose of neostigmine was increased to $1 \mathrm{mg}$ and later to $2 \mathrm{mgs}$ and cycles of neostigmine was continued till there was recovery from ptosis. Patient gradually showed improvement from ptosis, after total dose of $50 \mathrm{mg}$ of neostigmine, patient fully recovered from bilateral ptosis and was discharged.
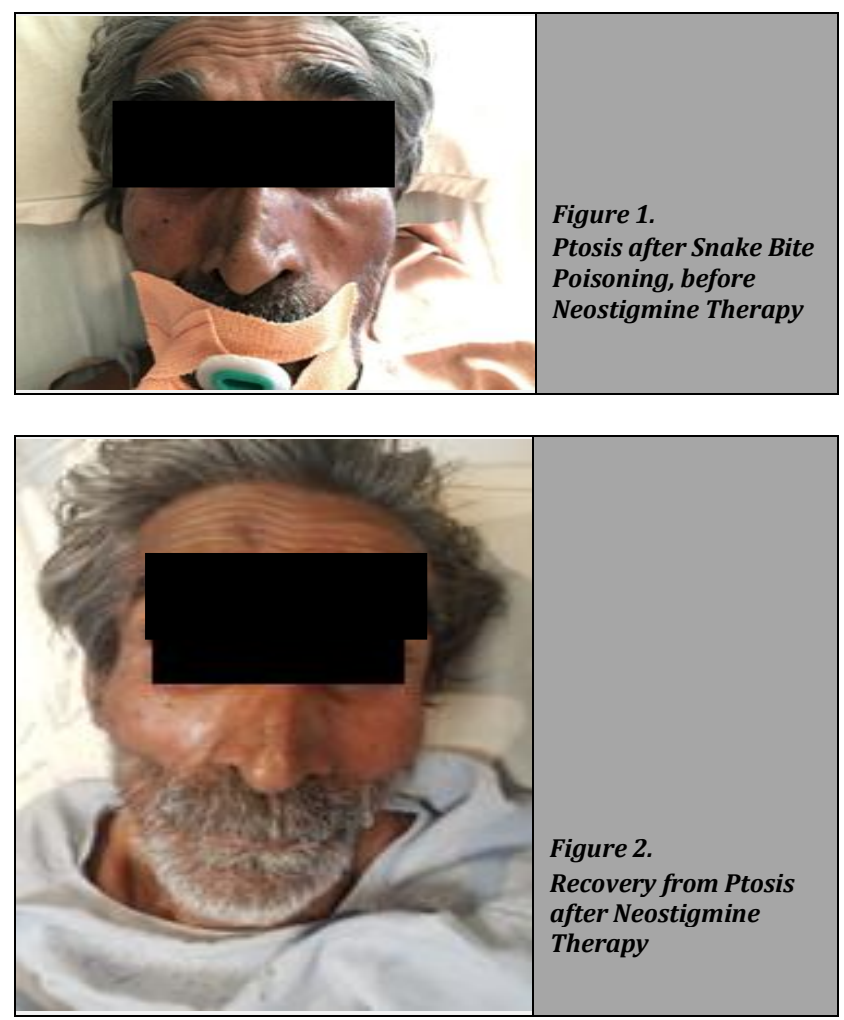

\section{DISCUSSION}

Neurotoxins (Cobra) attached to the acetyl-choline receptors on post synaptic membrane interfere with the opening of $\mathrm{Na}+$ channel and cause neuromuscular block, resulting in paralysis of the muscle. While in krait, toxin inhibits release of acetylcholine from presynaptic membrane. Neostigmine restores neuromuscular blockage by inhibiting acetylcholine esterase (enzyme which hydrolyse the acetylcholine) which prolongs the action of acetylcholine (cholinomimetic). [Figure
3] Neostigmine is able to antagonise the blockade, and has been shown to be very effective. ${ }^{5}$

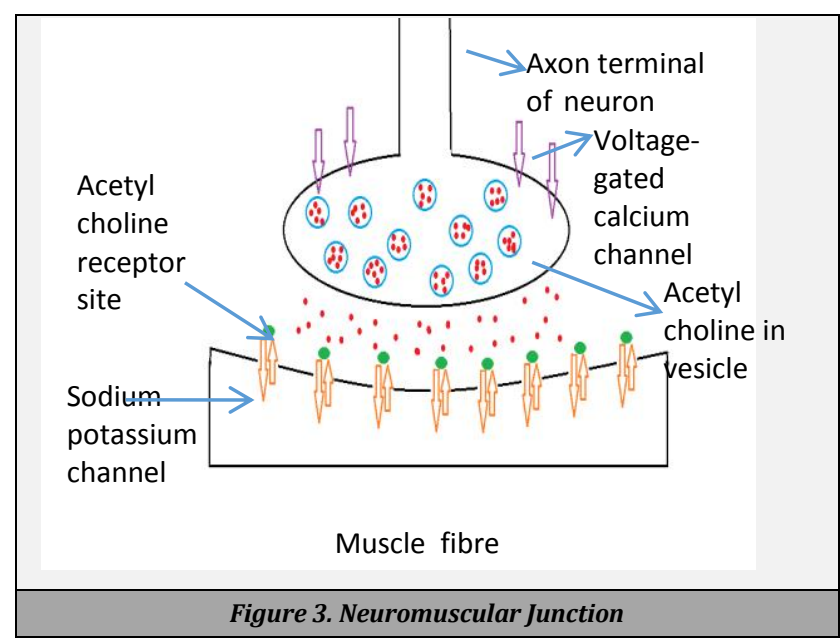

The venom causes stimulation of the autonomic nervous system within 20 to 30 minutes of the bite, victims have abdominal colicky pain, bradycardia, sweating, vomiting, raised blood pressure. ${ }^{5}$ Subsequently, within 30 minutes to 18 hours the venom attacks presynaptic acetylcholine receptors resulting in ptosis, pooling of saliva, dysphagia, dyspnoea, intern clear ophthalmoplegia, palatal weakness, weakness of neck muscles, respiratory muscles and lastly diaphragm. Patient has diplopia, blurred vision and goes into respiratory paralysis, coma and anoxic cardiac arrest.5,6 For reversing neuromuscular paralysis role of anticholinesterase is controversial. From Sri Lanka, Kularatne reported the failure of anticholinesterases and antivenom in reversing paralysis caused by Bungarus caeruleus.4,5 For diagnosis of @myasthenia gravis, snake bite protocol in India suggests single dose of intramuscular neostigmine along with atropine. ${ }^{6}$ This study recommends that for improving neuroparalytic effects, increasing the dosage regimen has no role. Neostigmine has no role in presynaptic envenoming. If snake is identified, neostigmine can be withheld from the treatment regimen. ${ }^{7}$ However, in this case $50 \mathrm{mg}$ of neostigmine was used to overcome the ptosis, contrary to published report. Pathology remains unclear. ${ }^{7}$

\section{CONCLUSIONS}

For improving neurological manifestation like ptosis in a patient with Bungarus caeruleus bite, higher doses of neostigmine are recommended.

Financial or other competing interests: None.

Disclosure forms provided by the authors are available with the full text of this article at jemds.com.

\section{REFERENCES}

[1] Ranawaka UK, Lalloo DG, De Silva HJ. Neurotoxicity in snakebite-the limits of our knowledge. PLoS Neglected Tropical Diseases 2013;7(10):e2302. 
[2] Gold BS. Neostigmine for the treatment of neurotoxicity following envenomation by the Asiatic cobra. Ann Emerg Med 1996;28(1):87-9.

[3] snakebite_management_in_emergencies.pdf [cited 2020 Oct

https://www.who.int/hac/crises/mmr/snakebite_mana gement_in_emergencies.pdf

[4] Brazil OV, Vieira RJ. Neostigmine in the treatment of snake accidents caused by Micrurus frontalis: report of two cases (1). Rev Inst Med Trop Sao Paulo 1996;38(1):61-7.
[5] Khan KI, Ghule A, Kumar S. Dry bite by common krait: a rare phenomenon \& its management: rationale use of antivenom. Medical Science 2020;24(104):2418-23.

[6] Anil A, Singh S, Bhalla A, et al. Role of neostigmine and polyvalent antivenom in Indian common krait (Bungarus caeruleus) bite. J Infect Public Health 2010;3(2):83-7.

[7] Oh AMF, Tan CH, Ariaranee GC, et al. Venomics of Bungarus caeruleus (Indian krait): comparable venom profiles, variable immunore activities among specimens from Sri Lanka, India and Pakistan. J Proteomics 2017;164:1-18. 